\title{
Predictors of weight loss in overweight veterans with knee osteoarthritis who participated in a clinical trial
}

\author{
Sarah Wolf, MPH, RD; ${ }^{1}$ Sharon Foley, PhD, RD; ${ }^{1 *}$ Elly Budiman-Mak, MD, MPH; ${ }^{1-2}$ Thomas Moritz, MS; $^{1}$ \\ Susan O’Connell, RN, MHA; ${ }^{1}$ Christine Jelinek, MS; ${ }^{1}$ Eileen G. Collins, RN, PhD ${ }^{1,3}$ \\ ${ }^{1}$ Edward Hines, Jr. Department of Veterans Affairs Hospital, Hines, IL; ${ }^{2}$ Loyola University Stritch School of Medicine, \\ Maywood, IL; ${ }^{3}$ College of Nursing, University of Illinois at Chicago, Chicago, IL
}

\begin{abstract}
Individuals with osteoarthritis (OA) of the knee have a high prevalence of obesity. The objective of this study was to determine predictors of weight loss among participants with knee OA in a clinical trial. A secondary analysis of data from a randomized clinical trial was used. Multiple regression analysis was used to predict weight loss after identification of predictor variables from the data. Hypothesized predictors of weight loss included demographic, clinical, and behavioral characteristics. The only baseline variable that was significantly related to weight loss was the Center for Epidemiologic Studies Depression Scale (CES-D) score. The CES-D score was an independent predictor of weight loss at $16(p<0.01)$ and 32 weeks $(p<0.05)$. Receiving nutrition counseling was also predictive of weight loss at 16 weeks $(p<0.03)$. These two variables explained $24 \%$ and $22 \%$ of the variance in weight loss for weeks 16 and 32, respectively. Being less depressed and receiving nutritional counseling appeared predictive of weight loss in this group of veterans.
\end{abstract}

Clinical Trial Registration: ClinicalTrials.gov; Home-based exercise and nutrition program for pain control in overweight elderly osteoarthritics; ClinicalTrials.gov ID: NCT 00126737; http://clinicaltrials.gov/ct2/show/NCT00126737/.

Key words: depression, knee osteoarthritis, nutrition intervention, obesity, osteoarthritis, overweight, self-efficacy, stages of change, veterans, weight loss.

\section{INTRODUCTION}

Obesity is an epidemic of global proportions, with more than 1 billion people estimated to be overweight worldwide [1]. Sixty-four percent of adults in the United States are overweight [2]. A higher prevalence of obesity is found in veterans, with approximately 73 percent of male veterans and 68 percent of female veterans overweight [3]. Some known chronic medical conditions associated with overweight and obesity are type 2 diabetes, depression, hyperlipidemia, hypertension, heart disease, and osteoarthritis (OA) [4-6]. The medical costs associated with obesity in the United States account for approximately 10 percent of total medical expenditures [7].

Moderate weight loss of between 5 and 10 percent has been associated with improvement in many medical conditions [5-6]. Even weight loss of 1 to $2.4 \mathrm{~kg}$ can have positive effects on blood pressure [8], reduce associated

Abbreviations: $\mathrm{BMI}=$ body mass index; CES-D = Center for Epidemiologic Studies Depression Scale; LEARN = Lifestyle, Exercise, Attitudes, Relationships, Nutrition (program for weight control); OA = osteoarthritis; VA = Department of Veterans Affairs; WOMAC = Western Ontario and McMaster Universities (Osteoarthritis Index).

* Address all correspondence to Sharon Foley, PhD, RD; Edward Hines, Jr. VA Hospital, Nutrition, N\&FS (120D), 5000 S 5th Ave, Hines, IL 60141; 708-202-2343; fax: 708202-2252. Email: Sharon.Folev@va.gov

DOI:10.1682/JRRD.2009.08.0136 
symptoms of knee OA, and decrease the need for knee replacement surgery [9]. Self-efficacy, stage of change, and depression have been well documented to affect a person's ability to lose weight [10-14]. The more a person feels able to lose weight and the more ready to make lifestyle changes to lose weight, the more apt he or she is to do so. Marital status [15] and sex [16], as well as previous attempts to lose weight [16-18], may also influence successful weight loss. The beneficial effects of weight reduction for individuals with knee OA coupled with evidence from the literature supporting psychosocial attributes linked to successful weight loss prompted us to conduct a post hoc analysis to determine whether certain demographic, psychosocial, and nutritional characteristics were predictive of weight loss in participants who completed a clinical trial entitled "Home-based exercise and nutrition program for pain control in overweight elderly osteoarthritics" (OA clinical trial).

\section{METHODS}

Participants were eligible for inclusion in the OA clinical trial if they were older than 50; had documented OA of the knee(s) within the past 6 months; were symptomatic for knee pain for at least 6 months prior to study entry; complained of knee pain most days within the previous month; had evidence of OA of the knee according to the American College of Rheumatology; had at least "mild" pain on the Western Ontario and McMaster Universities (Osteoarthritis Index) (WOMAC) pain scale; had American Rheumatology Association functional class of I, II, or III; had a body mass index (BMI) $\geq 27$ and $\leq 40$; received approval for participation in the study by the study physician; and agreed to attend scheduled exercise and nutritional counseling sessions. One hundred forty-three participants were enrolled in the OA clinical trial. One hundred eleven participants were randomized into four treatment arms of the OA clinical trial: (1) nutrition counseling ( $n=27)$, (2) tailored exercise program for home ( $n=30)$, (3) both nutrition counseling and home exercise program $(n=29)$, and (4) usual care $(n=25)$ (Figure). Seventy-eight percent $(n=87)$ of the 111 randomized participants completed the study. Study personnel who completed weight loss outcome assessments were not blinded to patients' randomization assignments. Patients completed questionnaires independent of the investigators. Subjects from the OA clinical trial were included in this secondary analysis if data were available for both predictive, outlined in the "Predictive Variables" section, and the outcome variable.

\section{INTERVENTION MODALITIES}

\section{Nutrition Counseling}

Participants randomized to receive the nutrition counseling intervention received a weight control and behavioral intervention program that included a modified version of the Lifestyle, Exercise, Attitudes, Relationships, Nutrition or LEARN ${ }^{\circledR}$ Program for Weight Management [19-20]. The LEARN Program was modified to exclude the exercise component since exercise was a separate intervention received by participants in two of the four arms of the study. The remaining portions of the LEARN Program were applied during the study: they consisted of 16 lesson plans covering a variety of nutrition topics (e.g., portion control, tips for eating at restaurants, eating during stress) and included reading materials for the participants, monitoring forms, self-assessment quizzes, and establishment of individualized goals. Participants met with a dietitian weekly for 60 minutes for the first 16 weeks and biweekly thereafter for 8 weeks. Participants completed some of the activities outlined in LEARN workbooks and completed homework assignments with guidance from the dietitian. No specific diet was provided to participants by the dietitian. Modification of the participants' eating habits and dietary choices was individualized to meet their lifestyles with a patient-centered approach to counseling. In addition, participants were weighed weekly and given the opportunity to discuss any problems they were having with their weight loss efforts.

\section{Home-Based Exercise}

Participants randomized to receive the home-based exercise intervention participated in weekly 60-minute supervised exercise sessions for the first 16 weeks and biweekly exercise sessions thereafter for 8 weeks. Participants were instructed on proper techniques for exercises to be completed at home. They were also given detailed instructions on the type, frequency, and duration of exercises to complete for the upcoming week. The program included training in aerobic exercise (primarily Nordic walking), isometric and isotonic progressive resistance exercises, and stretching exercises that were to be performed in the home. 


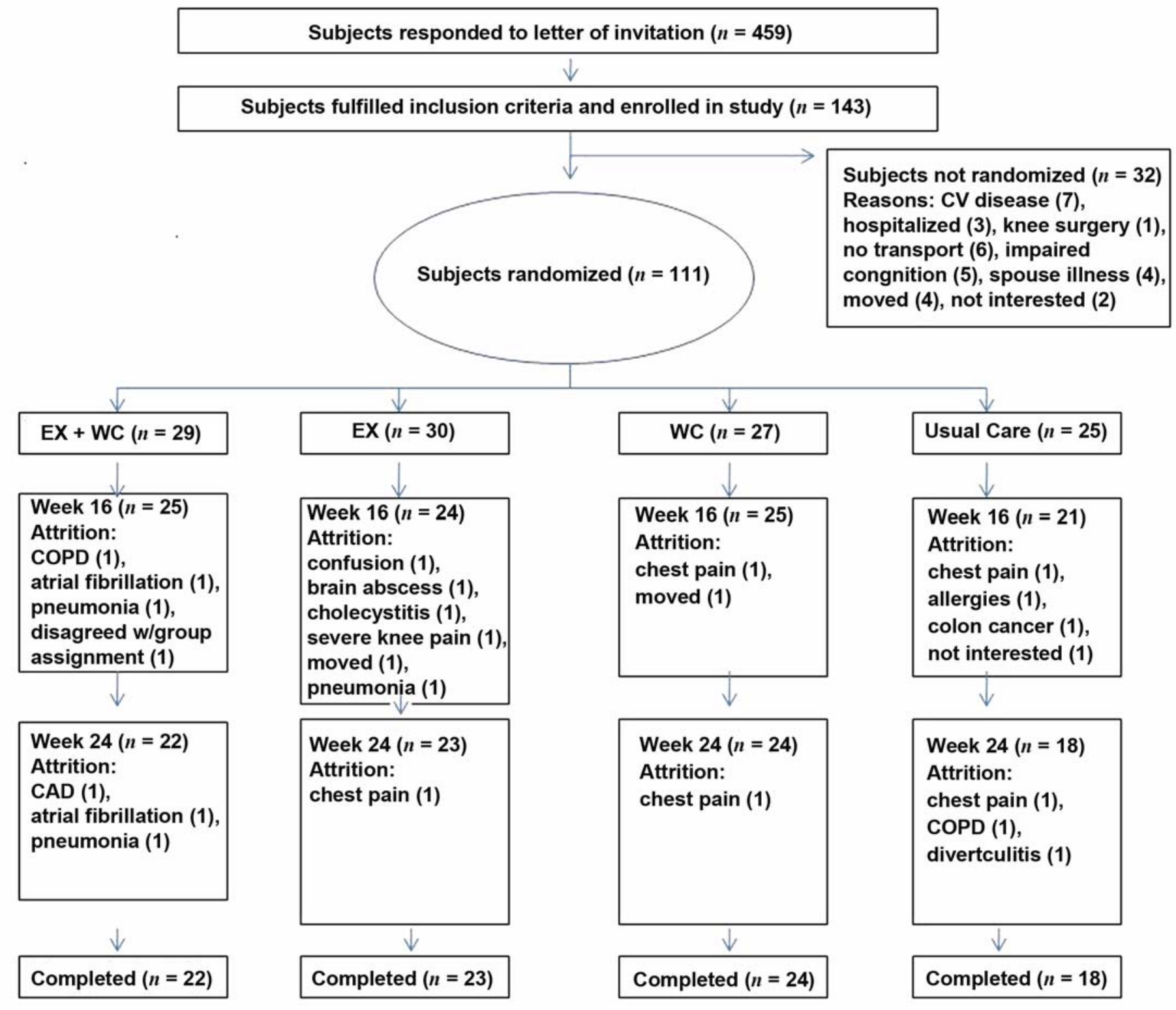

Figure.

Enrollment, randomization, and follow-up of osteoarthritis study participants. CAD = coronary artery disease, COPD $=$ chronic obstructive pulmonary disorder, $\mathrm{CV}=$ cardiovascular, $\mathrm{EX}=$ exercise program for home, $\mathrm{WC}=$ weight control (nutrition counseling), w/ = with.

\section{Nutrition and Home-Based Exercise}

Participants in this group received both the nutrition and exercise interventions as previously described.

\section{Usual Care}

The usual care group participated in weekly visits with the study staff for the first 16 weeks and biweekly visits thereafter for 8 weeks. They discussed general health-related issues such as medications and/or immuni- zations, information about future visits to various clinics, and continued follow-up with assigned primary care physicians. No nutrition or exercise counseling was provided.

\section{PREDICTIVE VARIABLES}

The following variables were measured at baseline and were selected for inclusion into exploratory data 
analyses based on findings from a literature review and their potential effect on and/or association with obesity and weight management.

\section{Depression}

The Center for Epidemiologic Studies Depression Scale (CES-D), a 20-item measure designed to evaluate symptoms of depression in the community population, was used to determine symptoms at baseline (Cronbach alpha $=0.85)$ [21]. The reported score uses continuous measures with a range of 0 to 60 ; a score of 16 or above is consistent with depression.

\section{Motivation}

Participants were asked to estimate their motivation to lose weight at baseline by marking off a point on a visual analog scale that had a zero at one end, an eight at the other end, and unmarked but equally spaced tick marks between the zero and eight. A higher score indicated greater motivation to lose weight. No reported psychometric properties are available for this tool.

\section{Self-Efficacy}

The Self-Efficacy to Regulate Eating Habits questionnaire (Cronbach alpha $=0.93$ ) contained 30 questions and used a modified version of the Weight Efficacy LifeStyle Questionnaire [11]. Participants were asked to rate their confidence in being able to "stick to healthy eating habits" when faced with different tempting situations using a scale of 0 (cannot do at all) to 10 (certain can do). The results from the questionnaire were then converted into interval measures using Rasch measurement, with a higher score indicating higher self-efficacy [22-23].

\section{Stages of Change}

The 42-item Stages of Change Modified Motivational Interviewing instrument (Cronbach alpha $=0.95$ ) was administered to participants regarding their readiness to change individual eating habits to lose weight [24]. Rasch measurement was used to convert responses from this questionnaire to interval measures. A higher score indicated more readiness to make behavioral changes to lose weight. Responses on the instrument were used by the dietitian to counsel and individually tailor weight loss messages according to the stage of change for a particular eating habit.

\section{History of Weight Loss Attempts}

At baseline, participants were asked how frequently they had attempted to lose weight in the past. Five response-option categories were provided. Responses were collapsed dichotomously into either positive history of previous weight loss attempts (responses of "trying fairly often," "frequently trying," and "always trying”) or lack of previous weight loss attempts ("never tried," “tried once”).

\section{Body Mass Index}

Subjects were measured for height using a stadiometer, and weight was obtained using a device that measures and tracks body weight, body fat, and lean mass using air displacement plethysmography, the BOD POD ${ }^{\circledR}$ (Life Measurement, Inc; Concord, California). Measured heights and weights were used to calculate BMI.

\section{Demographic Characteristics}

Marital status, sex, and race/ethnicity were also collected. For the purpose of this study, participants were identified as either married or not married and either white or nonwhite.

\section{OUTCOME VARIABLE: WEIGHT LOSS}

Weight loss was defined as weight changes that occurred between baseline and 16 weeks, as well as baseline and 32 weeks. Weight changes were measured quantitatively in pounds.

\section{DATA ANALYSIS}

Measures of central tendency were used to describe the sample and variables. Exploratory data analysis was conducted on the hypothesized predictive variables to determine which were significantly $(p \leq 0.05)$ associated with weight loss and to select for inclusion in multiple regression analysis. Pearson correlation statistics were used for continuous variables, and independent $t$-tests were used for dichotomous variables. Criteria for variables to be included in the regression model were liberalized $(p<0.2)$ in order to account for colinearity [25]. Multiple linear regression models were used to determine predictors of weight change. 
A backward, stepwise multiple linear regression model was used to determine which baseline psychosocial, nutritional, and clinical variables predicted weight loss at 16 and 32 weeks. Based on results from exploratory data analysis, the following predictive variables were included in the model: nutrition counseling group, marital status, motivation to lose weight score, CES-D score, and BMI. Since significantly more weight was lost by participants in the nutrition counseling intervention arms of the study, the four groups were collapsed into two groups and were analyzed as nutrition group (nutrition counseling intervention group and nutrition plus home-based exercise intervention group) versus nonnutrition group (usual care group and home-based exercise intervention group). All analyses were completed using SPSS, version 11.0 (SPSS, Inc; Chicago, Illinois).

\section{RESULTS}

\section{Baseline Descriptive Characteristics}

No statistically significant differences in demographic variables (age, sex, race/ethnicity, BMI, marital status) or psychosocial variables (CES-D, motivation, self-efficacy, or stage of change) were found between the four groups at baseline ( $p>0.05$, Table 1). Participants were older (mean age, $68 \pm 8 \mathrm{yr}$ ), mostly male (87\%), predominantly white $(89 \%)$, more likely to be married (60\%), and obese (mean BMI $34 \pm 6$; all data presented as mean \pm standard deviation unless otherwise noted). They had a mean CES-D score of $15 \pm 10$. Many of the participants (42\%) had a CES-D score consistent with depression $(\geq 16)$. The mean self-efficacy score for the entire study sample was $0.19 \pm 1.0$ logits, with a score of 0 as the midpoint indicating the scores were skewed toward the high end. The mean stage of change score was $0.20 \pm 0.73$ logits and showed good targeting of items to persons. Most of the participants (68\%) had a positive history of previous weight loss attempts.

\section{Outcomes for Entire Study and Between Groups}

The amount of weight loss for the entire study sample was modest at both $16(3.4 \pm 7.5 \mathrm{lb})$ and 32 weeks ( $4.3 \pm$ $11.1 \mathrm{lb}$ ), with no significant differences between any of the groups (Table 2). We also collapsed and compared the two groups that received nutrition intervention (nutrition counseling intervention group and nutrition counseling plus home-based exercise intervention group) with the two groups that did not receive nutrition counseling as an

Table 1.

Baseline characteristics of participants by treatment group. Data presented as mean \pm standard deviation or $n$ (\%).

\begin{tabular}{|c|c|c|c|c|c|}
\hline Variable & $\begin{array}{c}\text { Exercise }+ \\
\text { Weight Control } \\
\quad(n=29)\end{array}$ & $\begin{array}{l}\text { Exercise } \\
(n=30)\end{array}$ & $\begin{array}{l}\text { Weight Control } \\
\qquad(n=27)\end{array}$ & $\begin{array}{l}\text { Usual Care } \\
\quad(n=25)\end{array}$ & $\begin{array}{c}\text { Combined } \\
(n=111)\end{array}$ \\
\hline \multicolumn{6}{|l|}{ Demographic } \\
\hline Female & $3(10)$ & $4(13)$ & $4(15)$ & $3(12)$ & $14(13)$ \\
\hline White Race & $25(86)$ & $28(93)$ & $24(88)$ & $22(88)$ & 99 (89) \\
\hline \multicolumn{6}{|l|}{ Psychosocial } \\
\hline CES-D Score ${ }^{*}$ & $16 \pm 7$ & $15 \pm 10$ & $13 \pm 9$ & $17 \pm 10$ & $15 \pm 10$ \\
\hline Depressive Symptoms & $13(27)$ & $10(33)$ & $11(41)$ & $10(40)$ & $44(40)$ \\
\hline Motivation Score $^{\dagger}$ & $6.7 \pm 1.5$ & $6.9 \pm 1.0$ & $6.8 \pm 1.3$ & $6.6 \pm 1.3$ & $6.8 \pm 1.3$ \\
\hline
\end{tabular}


intervention (home-based exercise intervention group and usual care group). Participants in the two groups that received nutrition counseling had more weight loss at 16 weeks ( $p=0.04$ ) than participants in the groups that did not receive nutrition counseling. No significant differences were noted in weight loss between groups that received the exercise intervention and those that did not.

\section{Relationships Among Variables}

Pearson correlations were used to determine the relationships between continuous predictive baseline variables and the outcome variable (Table 3). Being less depressed was associated with weight loss at both 16 and 32 weeks, although these relationships were not strong. No other baseline predictive variables were significantly associated with the outcome variable.

\section{Differences Between Groups}

An independent $t$-test was used to compare differences in the outcome variable for the dichotomous variables marital status (married vs not married) and depression (measured with CES-D scores $\geq 16$ vs $<16$ ). Married participants tended to have more weight loss on average from baseline to 16 weeks than nonmarried participants, but this difference did not reach statistical significance. Partici- pants with CES-D scores reflecting no depression $(<16)$ lost more body weight at 16 and 32 weeks ( $p=0.007, p=$ 0.03 , respectively) than those with CES-D scores consistent with being depressed $(\geq 16)$.

\section{Predictors of Weight Loss}

Multiple linear regression models were used to identify predictors of weight loss. The baseline variables (CES-D score, self-perceived motivation to lose weight, baseline BMI, and marital status) were marginally associated with the outcome variable $(p<0.2)$. These baseline variables, as well as the dichotomous treatment variable nutrition counseling, were entered into the regression model, and the final model was determined using backward stepwise elimination. Of the five variables entered into the stepwise regression model, only two were significant predictors of weight loss. Being less depressed as determined by a lower CES-D score was an independent predictor of weight loss at $16(\beta=-0.36, p<0.01)$ and 32 weeks $(\beta=-0.28, p=0.04$ ) (Table 4). Receiving nutrition counseling also predicted weight loss at $16(\beta=$ $0.21, p=0.05)$ but not at 32 weeks $(\beta=0.20, p=0.08)$. The regression model that included both the CES-D score and receiving nutrition counseling explained 24 percent

Table 2.

Weight loss outcomes in osteoarthritis clinical trial participants at 16 and 32 weeks.

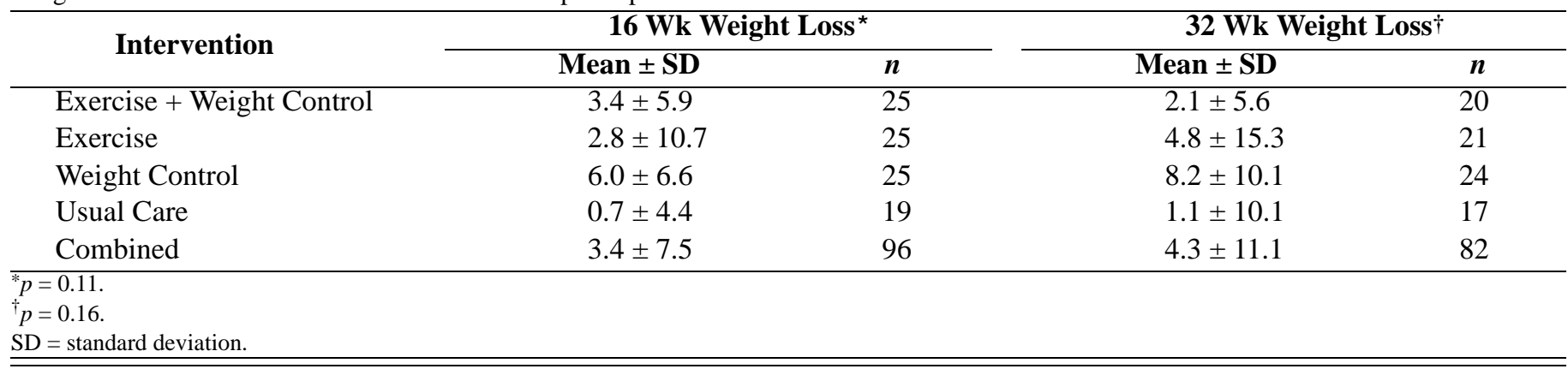

Table 3.

Relationship between baseline variables and change in weight.

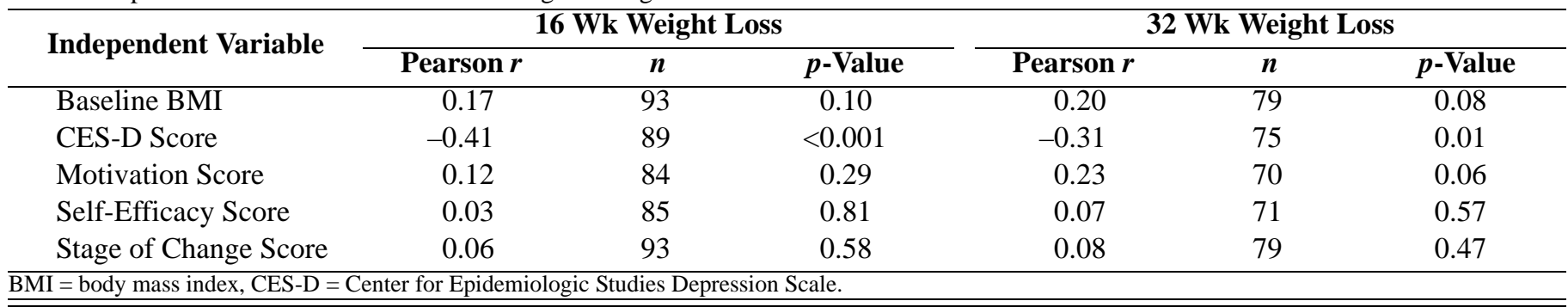


Table 4.

Multiple linear regression predictors of weight loss.

\begin{tabular}{|c|c|c|c|c|}
\hline \multirow{2}{*}{ Predictor } & \multicolumn{2}{|c|}{16 Wk Weight Loss* } & \multicolumn{2}{|c|}{32 Wk Weight Loss $\dagger$} \\
\hline & $\beta$ & $p$-Value & $\beta$ & $p$-Value \\
\hline Nutrition Group & 0.21 & 0.05 & 0.20 & 0.08 \\
\hline Baseline BMI & 0.18 & 0.09 & 0.23 & 0.06 \\
\hline Marital Status & 0.01 & 0.92 & -0.05 & 0.71 \\
\hline Motivation Score & 0.08 & 0.46 & 0.21 & 0.08 \\
\hline
\end{tabular}

of the variance in weight loss at 16 weeks. These same two variables explained 22 percent of the variance in weight loss at 32 weeks. The regression model for weight loss at 16 weeks was weight loss at 16 weeks (pounds) $=$ $4.82+(-0.36 \times$ CES-D score $)+(0.21 \times n)$, where $n=$ receiving nutrition counseling $(1=$ yes, $0=$ no). The regression model for weight loss at 32 weeks was weight loss at 32 weeks (pounds) $=15.93+(-0.28 \times$ CES-D score). Both race/ethnicity and sex were excluded in the analysis because of the limited number of participants of each sex and race/ethnicity. An interaction between the two treatments (nutrition counseling and exercise program) was explored and showed no significant interaction with any of the outcomes.

\section{DISCUSSION}

\section{Depression and Weight Loss}

This study suggests that having a lower CES-D score (being less depressed) may have played a part in predicting weight loss during intervention among older obese males with chronic knee OA. This finding is consistent with results from other studies [14,26-27]. Depression has been identified as a predictive factor of nonadherence to treatment for multiple medical conditions and specifically for nonadherence to weight loss behaviors, such as improving diet and increasing physical activity [14,2627]. In addition, depression may interact with other factors, such as self-esteem and self-efficacy, that influence adherence. Depressed patients often feel isolated and hopeless, making them less likely to see the possible positive outcomes of behavior change. Since depression and obesity are thought to have a bidirectional association, whether depression should be treated prior to encourag- ing behavior changes for weight loss or whether the weight loss program might serve as treatment for depression in the obese patient is unknown [28-30].

A higher percentage (42\%) of our study sample screened positive for depression than a national sample of veterans (31\%) [29,31]. The depression rate for the U.S. population older than 65 is 26 percent [31]. One possible reason for the higher scores on the CES-D in our sample was that 41 percent of our participants were Vietnam era veterans: a group known to have a high prevalence of depression and other mental health problems [32]. Another contributing factor to more depression is that patients with chronic OA of the knee experience much pain, resulting in limited mobility and disability from multiple comorbidities. The incidence of depression in individuals who are trying to lose weight may be an important criterion in planning interventions for successful weight loss.

\section{Body Mass Index}

At baseline, the mean BMI was comparable to that of participants in other weight loss interventions [15,33]. While baseline BMI trended toward being predictive of weight loss at 16 weeks, this relationship was not significant. One might expect a person with a higher BMI at baseline to lose weight more rapidly than one with a lower BMI [16]; we investigated weight loss as both the total number of pounds lost as well as the percentage of body weight that the person lost in relation to their initial body weight in attempt to account for the fact that those who are heavier often lose more weight faster. However, results using the percentage of weight lost did not seem to affect our results, and thus, weight loss as a percentage of initial weight was not reported. Although the weight loss was less than the recommended 10 percent over 
6 months [2,5], our results are similar to those found in other studies conducted on veterans [13]. Our study may not have had enough statistical power to detect a significant relationship between BMI and weight loss. Perhaps the higher rate of depression in our sample reduced the impact on weight loss. Lack of group support and less rigorous accountability of patients to the study program may have accounted for minimal weight loss. Treatment programs that emphasize behavior modification and cognitive strategies to lose weight are more successful when social support is present [13,34-35].

\section{Self-Efficacy}

Baseline self-efficacy scores were not correlated with weight loss. However, self-efficacy has been established as an important predictor of change in many health behaviors, including weight loss $[10,18,36]$. Baseline measures may not be as important as changes in self-efficacy over time in the program, and results supporting this have been reported from other studies involving overweight and obese individuals [10,37].

\section{Stage of Change}

Baseline stage of change scores were also not correlated with weight loss. Since stage of change can vary significantly over time, a better predictor may have been the relationship between stage of change scores and body weight over the same time frame. Again, baseline measures may not be as important as the movement through the stages of change for predicting success at weight loss. Evidence varies as to whether interventions that match treatment to stage of change are more successful than those that do not take stage of change into account [3839]. Measuring stage of change for weight loss is difficult at best [12,40-41]. Our stage of change measures appeared to be associated more with adherence to the intervention than to the weight loss outcome. This information may be helpful as a strategy for improving the effectiveness of the intervention.

\section{Overall Model}

Overall, 24 percent of the variance in weight loss was explained by our model. Other factors, not included in the model, may account for why people with OA of the knee do or do not lose weight. Perhaps the higher rate of depression in our sample reduced the impact on weight loss. Although baseline pain of the participants was mild as measured with the WOMAC pain scale, pain may have been a mediator for depression or it may have negatively influenced physical functioning and weight control efforts. Lack of group support and less rigorous accountability of patients to the study program may have accounted for minimal weight loss. Treatment programs that emphasize behavior modification and cognitive strategies to lose weight are more successful when social support is present [13,34-35].

Limitations of the study include the small sample size that may have contributed to a type II error. Several of the measures used in this study did not have published psychometric properties reported in the literature. Although the drop-out rate for this study was similar (22\%) to other studies [18,35], the small sample size may have reduced the statistical power to detect differences between the groups on the outcome measure. Also, the post hoc nature of this study did not allow us to investigate other variables associated with successful weight loss. A person's ability to lose weight is multifactorial in its etiology, and without investigating all aspects, predicting factors that lead to successful weight loss is difficult. In addition, the amount of weight lost within the groups did not vary by a large amount, which also contributed to making weight loss prediction difficult. Considering that the OA clinical trial investigated the effects of exercise on pain as the primary outcome variable, pain and adherence to the study program could have accounted for some of the variance in weight loss.

\section{CONCLUSIONS}

Of all the psychosocial factors that were examined, only depression and receiving nutrition counseling appeared to predict weight loss in this group of veterans with OA of the knee. This finding suggests that depression should be treated as a critical factor in the design and development of future weight loss programs for veterans. Other behavioral factors did not play a significant role as hypothesized. Depression and receiving nutrition counseling accounted for a small amount of the variance in the weight loss outcome, suggesting that other factors or a combination of factors may be accountable for weight loss. Because the primary outcome variable of the OA clinical trial was the effect of exercise on pain, pain could have accounted for some of the variance in the outcome measure of weight loss as well as for the rate of patient drop out from the study. The drop-out rate may also have reduced the study's power to detect differences between the groups. Thus, 
research investigating the interaction between depression, pain, and weight loss may hold much interest in the future.

\section{ACKNOWLEDGMENTS}

\section{Author Contributions:}

Study concept and design: S. Foley, E. Budiman-Mak, E. G. Collins. Acquisition of data: S. Wolf, S. Foley, E. Budiman-Mak, S. O’Connell, C. Jelinek, E. G. Collins.

Analysis and interpretation of data: S. Wolf, S. Foley, E. BudimanMak, E. G. Collins.

Drafting of manuscript: S. Wolf, S. Foley, E. Budiman-Mak, E. G. Collins.

Critical revision of manuscript for important intellectual content: S. Wolf, S. Foley, E. Budiman-Mak, S. O’Connell, E. G. Collins. Statistical analysis: S. Wolf, S. Foley, E. Budiman-Mak, T. Moritz, E. G. Collins.

Obtained funding: S. Foley, E. Budiman-Mak, E. G. Collins. Administrative, technical, or material support: S. Foley, E. BudimanMak, S. O’Connell, C. Jelinek, E. G. Collins.

Study supervision: S. Foley, E. Budiman-Mak, E. G. Collins.

Financial Disclosures: The authors have declared that no competing interests exist.

Funding/Support: This material was based on work supported by Department of Veterans Affairs (VA) Rehabilitation Research and Development Service, grant E2-2362RA.

Additional Contributions: Scott Miskevics for data cleaning and analysis, and Renee Margaron, RD, for nutrition counseling and data collection. Sara Wolf, MPH, RD, is now with the New York City Department of Health and Mental Hygiene.

Institutional Review: The Edward Hines, Jr. VA Hospital Institutional Review Board approved this study. Each participant signed informed consent before entering the study.

Participant Follow-Up: The authors do not plan to notify study subjects of the publication of this article because of a lack of contact information.

\section{REFERENCES}

1. World Health Organization (WHO). The World Health Organization warns of the rising threat of heart disease and stroke as overweight and obesity increase [Internet]. Geneva (Switzerland): WHO; 2005 Sep 22 [cited 2007]. 2 screens. Available from: http://www.who.int/mediacentre/news/releases/2005/pr44/en/index.html.

2. Centers for Disease Control and Prevention, National Center for Health Statistics. National Health and Nutrition Examination Survey, Healthy weight, overweight, and obesity among U.S. adults. [Internet]. Atlanta (GA): CDC; 2005 [cited 2007]. 2 p. Available from: http://cdc.gov/nchs/data/ nhanes/databriefs/adultweight.pdf.
3. Das SR, Kinsinger LS, Yancy WS Jr, Wang A, Ciesco E, Burdick M, Yevich SJ. Obesity prevalence among veterans at Veterans Affairs medical facilities. Am J Prev Med. 2005; 28(3):291-94. [PMID: 15766618]

DOI:10.1016/j.amepre.2004.12.007

4. Department of Veterans Affairs. 2001 National Survey of Veterans, Final Reports [Internet]. Washington (DC): Department of Veterans Affairs; 2007 [cited 2007]. Available from: http://www1.va.gov/VETDATA/SurveysAndStudies/Final Report.asp.

5. Executive summary of the clinical guidelines on the identification, evaluation, and treatment of overweight and obesity in adults. Arch Intern Med. 1998;158(17):1855-67. [PMID: 9759681] DOI:10.1001/archinte.158.17.1855

6. Vidal J. Updated review on the benefits of weight loss. Int J Obes Relat Metab Disord. 2002;26 Suppl 4:S25-28. [PMID: 12457296] DOI:10.1038/sj.ijo.0802215

7. Finkelstein EA, Fiebelkorn IC, Wang G. National medical spending attributable to overweight and obesity: How much, and who's paying? Health Aff (Millwood). 2003;Suppl Web Exclusives:W3-219-26. [PMID: 14527256]

8. Grimm RH Jr, Cohen JD, Smith WM, Falvo-Gerard L, Neaton JD. Hypertension management in the Multiple Risk Factor Intervention Trial (MRFIT). Six-year intervention results for men in special intervention and usual care groups. Arch Intern Med. 1985;145(7):1191-99.

[PMID: 3893343]

DOI:10.1001/archinte.145.7.1191

9. Messier SP, Loeser RF, Miller GD, Morgan TM, Rejeski WJ, Sevick MA, Ettinger WH Jr, Pahor M, Williamson JD. Exercise and dietary weight loss in overweight and obese older adults with knee osteoarthritis: The Arthritis, Diet, and Activity Promotion Trial. Arthritis Rheum. 2004;50(5): 1501-10. [PMID: 15146420]

DOI:10.1002/art.20256

10. Bandura A, Locke EA. Negative self-efficacy and goal effects revisited. J Appl Psychol. 2003;88(1):87-99.

[PMID: 12675397] DOI:10.1037/0021-9010.88.1.87

11. Clark MM, Abrams DB, Niaura RS, Eaton CA, Rossi JS. Self-efficacy in weight management. J Consult Clin Psychol. 1991;59(5):739-44. [PMID: 1955608]

DOI:10.1037/0022-006X.59.5.739

12. Jeffery RW, French SA, Rothman AJ. Stage of change as a predictor of success in weight control in adult women. Health Psychol. 1999;18(5):543-46. [PMID: 10519471] DOI:10.1037/0278-6133.18.5.543

13. Prochaska JO, Norcross JC, Fowler JL, Follick MJ, Abrams DB. Attendance and outcome in a work site weight control program: Processes and stages of change as process and predictor variables. Addict Behav. 1992;17(1):35-45. 
[PMID: 1595424$]$

DOI:10.1016/0306-4603(92)90051-V

14. Wing RR, Phelan S, Tate D. The role of adherence in mediating the relationship between depression and health outcomes. J Psychosom Res. 2002;53(4):877-81. [PMID: 12377297] DOI:10.1016/S0022-3999(02)00315-X

15. Adolfsson B, Andersson I, Elofsson S, Rössner S, Undén AL. Locus of control and weight reduction. Patient Educ Couns. 2005;56(1):55-61. [PMID: 15590223] DOI:10.1016/j.pec.2003.12.005

16. Bautista-Castaño I, Molina-Cabrillana J, Montoya-Alonso JA, Serra-Majem L. Variables predictive of adherence to diet and physical activity recommendations in the treatment of obesity and overweight, in a group of Spanish subjects. Int J Obes Relat Metab Disord. 2004;28(5):697-705. [PMID: 14993911] DOI:10.1038/sj.ijo.0802602

17. Kiernan M, King AC, Kraemer HC, Stefanick ML, Killen JD. Characteristics of successful and unsuccessful dieters: An application of signal detection methodology. Ann Behav Med. 1998;20(1):1-6. [PMID: 9755345$]$

DOI:10.1007/BF02893802

18. Teixeira PJ, Going SB, Houtkooper LB, Cussler EC, Metcalfe LL, Blew RM, Sardinha LB, Lohman TG. Pretreatment predictors of attrition and successful weight management in women. Int J Obes Relat Metab Disord. 2004;28(9):1124-33. [PMID: 15263921]

DOI:10.1038/sj.ijo.0802727

19. Brownell KD. The LEARN program for weight management 2000. Dallas (TX): American Health Publishing Co; 2000.

20. Brownell KD, Kramer FM. Behavioral management of obesity. Med Clin North Am. 1989;73(1):185-201. [PMID: 2643003]

21. Radloff LS. The CES-D scale: A self-report depression scale for research in the general population. Appl Psychol Measurement. 1977;1:385-401. DOI:10.1177/014662167700100306

22. Rasch G. Probabilistic models for some intelligence and achievement tests. Chicago (IL): Chicago University Press; 1960.

23. Wolfe EW, Smith EW Jr. Rasch measurement: Advanced and specialized applications. In: Smith EV Jr, Smith RM, editors. Instrument development tools and activities for measure validation using Rasch Models: Part II-Validation activities. Maple Grove (MN): JAM Press; 2007. p. 243-290.

24. Foley S. Psychometric properties of data from measure designed to assess stage of change for eating behaviors [dissertation]. Chicago (IL): University of Illinois at Chicago; 2009.

25. Steyerberg EW, Eijkemans MJ, Harrell FE Jr, Habbema JD. Prognostic modelling with logistic regression analysis: A comparison of selection and estimation methods in small data sets. Stat Med. 2000;19(8):1059-79. [PMID: 10790680] DOI:10.1002/(SICI)1097-0258(20000430)19:8<1059::AID$\underline{\text { SIM412>3.0.CO;2-0 }}$

26. Ciechanowski PS, Katon WJ, Russo JE. Depression and diabetes: Impact of depressive symptoms on adherence, function, and costs. Arch Intern Med. 2000;160(21):3278-85.

[PMID: 11088090]

DOI:10.1001/archinte.160.21.3278

27. Ziegelstein RC, Fauerbach JA, Stevens SS, Romanelli J, Richter DP, Bush DE. Patients with depression are less likely to follow recommendations to reduce cardiac risk during recovery from a myocardial infarction. Arch Intern Med. 2000;160(12):1818-23. [PMID: 10871976] DOI:10.1001/archinte.160.12.1818

28. Daly J, Sindone AP, Thompson DR, Hancock K, Chang E, Davidson P. Barriers to participation in and adherence to cardiac rehabilitation programs: A critical literature review. Prog Cardiovasc Nurs. 2002;17(1):8-17. [PMID: 11872976] DOI:10.1111/j.0889-7204.2002.00614.X

29. Hankin CS, Spiro A 3rd, Miller DR, Kazis L. Mental disorders and mental health treatment among U.S. Department of Veterans Affairs outpatients: The Veterans Health Study. Am J Psychiatry. 1999;156(12):1924-30. [PMID: 10588406]

30. Park NH, An HG. Effects of the weight management program based self-efficacy for body composition, blood lipid profile, weight self-efficacy lifestyles, depression in middle-aged obese women. Taehan Kanho Hakhoe Chi. 2006; 36(8):1359-66. [PMID: 17215609]

31. National Institute of Mental Health (NIMH). Older adults: Depression and suicide facts (Fact Sheet) [Internet]. [updated 2009 May 18; cited 2009]. Washington (DC): NIMH; 2003. Available from: http://www.nimh.nih.gov/ health/publications/older-adults-depression-and-suicidefacts-fact-sheet/index.shtml.

32. Health status of Vietnam veterans. I. Psychosocial characteristics. The Centers for Disease Control Vietnam Experience study. JAMA. 1988;259(18):2701-7. [PMID: 2833630] DOI:10.1001/jama.259.18.2701

33. Kumanyika SK, Espeland MA, Bahnson JL, Bottom JB, Charleston JB, Folmar S, Wilson AC, Whelton PK; TONE Cooperative Research Group. Ethnic comparison of weight loss in the trial of nonpharmacologic interventions in the elderly. Obes Res. 2002;10(2):96-106. [PMID: 11836455] DOI:10.1038/oby.2002.16

34. Parham ES. Enhancing social support in weight loss management groups. J Am Diet Assoc. 1993;93(10):1152-58. [PMID: 8068056] DOI:10.1016/0002-8223(93)91648-A

35. Wing RR, Jeffery RW. Benefits of recruiting participants with friends and increasing social support for weight loss and maintenance. J Consult Clin Psychol. 1999;67(1):132-38. 
[PMID: 10028217]

DOI:10.1037/0022-006X.67.1.132

36. Wamsteker EW, Geenen R, Iestra J, Larsen JK, Zelissen PM, Van Staveren WA. Obesity-related beliefs predict weight loss after an 8-week low-calorie diet. J Am Diet Assoc. 2005;105(3):441-44. [PMID: 15746833] DOI:10.1016/j.jada.2004.12.031

37. Martin PD, Dutton GR, Brantley PJ. Self-efficacy as a predictor of weight change in African-American women. Obes Res. 2004;12(4):646-51. [PMID: 15090632] DOI:10.1038/oby.2004.74

38. Logue E, Sutton K, Jarjoura D, Smucker W, Baughman K, Capers C. Transtheoretical model-chronic disease care for obesity in primary care: A randomized trial. Obes Res. 2005; 13(5):917-27. [PMID: 15919846]

DOI:10.1038/oby.2005.106
39. Van der Veen J, Bakx C, Van den Hoogen H, Verheijden M, Van den Bosch W, Van Weel C, Van Staveren W. Stagematched nutrition guidance for patients at elevated risk for cardiovascular disease: A randomized intervention study in family practice. J Fam Pract. 2002;51(9):751-58.

[PMID: 12366892]

40. Hawkins DS, Hornsby PP, Schorling JB. Stages of change and weight loss among rural African American women. Obes Res. 2001;9(1):59-67. [PMID: 11346668] DOI:10.1038/oby.2001.8

41. Kristal AR, Glanz K, Curry SJ, Patterson RE. How can stages of change be best used in dietary interventions? J Am Diet Assoc. 1999;99(6):679-84. [PMID: 10361529] DOI:10.1016/S0002-8223(99)00165-0

Submitted for publication August 27, 2009. Accepted in revised form January 21, 2010. 
